\title{
A indústria da construção pesada do Rio de Janeiro no século XX: protagonismo, tensões políticas e decadência
}

The Rio de Janeiro heavy construction industry in the tewntieth century:protagonism, political tensions and decadence

La industria de la construcción pesada de Río de Janeiro en el siglo XX:

protagonismo, tensiones políticas y decadencia

L'industrie de la construction lourde de Rio de Janeiro au XXe siècle:

protagonisme, tensions politiques et décadence

\section{Pedro Henrique Pedreira Campos}

\section{(2) OpenEdition}

Journals

Edição electrónica

URL: http://journals.openedition.org/espacoeconomia/3356

DOI: $10.4000 /$ espacoeconomia.3356

ISSN: 2317-7837

Editora

Núcleo de Pesquisa Espaço \& Economia

Refêrencia eletrónica

Pedro Henrique Pedreira Campos, «A indústria da construção pesada do Rio de Janeiro no século XX: protagonismo, tensões políticas e decadência », Espaço e Economia [Online], 12 | 2018, posto online no dia 14 julho 2018, consultado o 19 abril 2019. URL : http://journals.openedition.org/ espacoeconomia/3356; DOI : 10.4000/espacoeconomia.3356

Este documento foi criado de forma automática no dia 19 Abril 2019.

(c) NUPEE 


\title{
A indústria da construção pesada do Rio de Janeiro no século XX: protagonismo, tensões políticas e decadência
}

\author{
The Rio de Janeiro heavy construction industry in the tewntieth \\ century:protagonism, political tensions and decadence \\ La industria de la construcción pesada de Río de Janeiro en el siglo XX: \\ protagonismo, tensiones políticas y decadencia \\ L'industrie de la construction lourde de Rio de Janeiro au XXe siècle: \\ protagonisme, tensions politiques et décadence
}

Pedro Henrique Pedreira Campos

1 Este artigo propõe abordar a indústria da construção pesada originada na cidade do Rio de Janeiro ao longo do século XX. Analisaremos a trajetória do setor e de algumas das mais importantes empreiteiras cariocas que atuaram no Rio, no Brasil e no exterior principalmente a partir dos anos 1920 e 1930, quando boa parte delas foi fundada, até o final do século, centrando esforços nos anos 1950, 1960 e no período da ditadura civilmilitar (1964-1988). Focaremos as firmas do ramo da construção pesada, ou melhor, as empresas dedicadas à realização das obras de infra-estrutura em ramos como transportes, energia e saneamento, ou seja, construtoras responsáveis pela realização de projetos como rodovias, ferrovias, portos, aeroportos, usinas hidrelétricas, termoelétricas, intervenções urbanas e outros empreendimentos.

2 Estamos entendendo esse ramo econômico como um segmento industrial. Apesar de muitas vezes esse setor ser enquadrado na área de serviços, compreendemos a construção pesada como uma atividade fabril que congrega trabalho humano e o uso de máquinas para a transformação de matérias-primas (aço, cimento, madeira, asfalto etc.) em mercadorias específicas, no caso, a obra pronta - uma estrada de rodagem, uma rede de 
esgotos, um túnel, uma ponte etc (CHAVES, 1985; ALMEIDA, DAIN; ZONINSEIN, 182; CAMPOS, 2014).

3 Apesar de ter sido até 1960 a capital federal e, aproximadamente até esse período, a maior cidade brasileira, o Rio de Janeiro não contava ao final do século XX com as maiores empresas de engenharia do país. Mesmo continuando a ser sede de algumas das principais contratantes de obras públicas, sendo um importante espaço para empreendimentos imobiliários e tendo uma posição importante no mercado nacional de infraestrutura, o estado do Rio viu suas empresas serem superadas pelas maiores empresas vindas de São Paulo, Minas Gerais e até mesmo do Paraná e do Nordeste. Assim, nossas atenções nesse artigo se voltam justamente a tentar desvendar o motivo dessa submersão das empresas fluminenses frente a outras de diferentes regiões do país.

4 Para isso, usamos como fontes de pesquisa revistas técnicas do setor, como o periódico 0 Empreiteiro, documentos e dados das organizações empresariais do ramo, bem como memórias de agentes que atuaram no setor de construção civil brasileira no século XX. Para a análise desse setor e da trajetória das empresas, advogamos pela premissa da totalidade, entendendo que as questões de ordem econômica não podem ser compreendidas sem se levar em questões problemas de ordem política e social (VILAR, 1976; MARX, 1974 [1857]). Assim, como veremos, nossa hipótese gira em torno da leitura de que a decadência das empresas cariocas e fluminenses no mercado nacional de construção civil ao longo do século XX não resulta apenas de problemas de desempenho das empresas, estratégias equivocadas de seus controladores e dirigentes ou como fruto das forças do mercado. Entendemos que questões de ordem política e que dizem respeito à própria correlação de forças na sociedade brasileira ajudaram no movimento de falência e recuo de algumas empresas fluminenses, bem como beneficiaram algumas delas e outras em certas situações.

5 Para dar conta dessa ordem de questões, traçamos o seguinte roteiro para o ensaio. Em um primeiro momento, faremos uma breve exposição acerca da trajetória histórica do setor da indústria de construção no Brasil ao longo do século XX, enfatizando o segmento de infra-estrutura. Em uma segunda parte, analisamos as especificidades do processo desse ramo econômico no estado nesse mesmo período, enfatizando a dinâmica da cidade do Rio. Por fim, com mais detalhamento e profundidade, abordamos a trajetória de algumas das principais empreiteiras cariocas ao longo do século, tecendo considerações sobre seus controladores, período de funcionamento, principais projetos tocados e condições que levaram à decadência de algumas delas. A partir dessas considerações, tentaremos ao final do artigo tecer uma síntese acerca do processo histórico do setor e das empresas de construção civil da cidade do Rio de Janeiro, propondo uma explicação e leitura acerca dos impasses por que passa o setor e o próprio estado no início do século XXI.

\section{O setor de construção civil no Brasil ao longo do século XX}

O setor de construção civil no início do século XX era bastante incipiente e tímido no Brasil. Fruto dos desdobramentos da Revolução Industrial, a indústria da construção constituía um segmento econômico que tinha papel menor e subsumido à própria dinâmica predominante das atividades produtivas no país. Como um país 
fundamentalmente especializado na produção de itens primários, sobretudo voltados à exportação, a indústria da construção no Brasil desempenhava um papel de suporte às atividades de escoamento dos produtos dedicados ao comércio exterior e sua inserção no mercado mundial, com a velocidade que a demanda e o processo de reprodução do capital demandavam.

7 Nesse sentido, as principais atividades em termos de empreendimentos de infra-estrutura no país nas três primeiras décadas do século diziam respeito ao processo de transporte de mercadorias, embarque nos portos e na dinâmica das cidades brasileiras, ainda pequenas e dominadas no período pelo predomínio das atividades rurais. As empresas de engenharia atuavam muitas vezes na construção, melhoramento e manutenção de ferrovias, construção e ampliação dos portos e no atendimento das necessidades urbanas.

Dado que o Brasil era uma economia predominantemente dependente no sistema internacional, as principais obras feitas nesse campo eram tocadas principalmente por empresas estrangeiras, a partir de tecnologia e experiência internacionais e com equipamentos, pessoal e até mesmo materiais vindos sobretudo do exterior. Apesar de o país já contar no período com as suas escolas de engenharia e pequenas empresas do setor, prevaleciam as firmas de fora. E mesmo as obras de infra-estrutura eram demandadas predominantemente por parte de empresas internacionais. Assim, grupos como a The Rio de Janeiro Tramway, Light and Power Company Limited, ou somente Light, e a American Foreign \& Power, ou Amforp, demandavam serviços como a construção de usinas de energia, redes de transmissão e distribuição, transportes urbanos (bondes), sistema de telefones e telégrafos, fornecimento de gás encanado, dentre outros serviços (CASTRO, 1979; SAES, 1986).

9 A lógica do funcionamento do setor se modificou com os choques internacionais da "Era da Catástrofe" (HOBSBAWM, 1998) e da assim chamada industrialização por substituição de importações. Com as dificuldades para importar e a escassez de produtos e serviços antes comprados no exterior para o atendimento do mercado interno, a ação estatal na economia passou a se modificar e assumiu a forma do intervencionismo e da ação das autarquias e empresas estatais, predominantemente a partir dos anos 1930. Essas novas agências do Estado em certa medida substituíram as grandes empresas estrangeiras como as principais contratadoras de obras de infra-estrutura e passaram a demandar serviços de engenharia para a montagem da base do novo eixo de acumulação de capital no país, mais dedicado ao mercado interno e deslocado em seu epicentro rural para o ramo urbano-industrial (TAVARES, 1978; FURTADO, 2000).

Dessa forma, nos anos 1930, 1940 e 1950 foram fundadas importantes agências estatais que passaram a figurar como contratadoras de obras públicas, como o Departamento Nacional de Estradas de Rodagem (1937), Companhia Hidrelétrica do Vale do São Francisco (1945), Petrobrás (1953), Furnas Centrais Elétricas (1957), além das companhias e autarquias em nível estadual. Nas décadas de 1960 e 1970, outras importantes estatais foram fundadas, como a Eletrobrás (1962), o Banco Nacional de Habitação (1964) e a Embratel (1965). Essas agências davam preferência para a contratação de empresas brasileiras, seja pela orientação de fortalecer os grupos privados do país, seja pela própria influência e inserção que os empresários do ramo da engenharia possuíam junto a essas agências. Com isso, formou-se um mercado de obras públicas com os serviços demandados por parte dessas agências (DRAIBE, 1985; CAMPOS, 2014). 
11 Alguns momentos dessa trajetória merecem destaque. Em primeiro lugar, é importante apontar o pioneirismo de certos governos e das ações de certas unidades da federação. Assim, São Paulo e Minas Gerais nas décadas de 1930, 1940 e 1950 montaram importantes projetos de modernização da sua infraestrutura econômica, na forma de empreendimentos de transportes e energia. Esses se expressavam sobretudo na forma da obra de construção da rodovias e na geração de energia a partir de usinas hidrelétricas, além das redes de transmissão e distribuição. Com isso, foram formadas importantes agências estatais demandantes de serviços a empresas de engenharia, como o Departamento de Estradas de Rodagem de São Paulo (DER-SP), de Minas (DER-MG), além das Centrais Elétricas de Minas Gerais (Cemig) e Centrais Elétricas de São Paulo (Cesp). Essas agências tendiam a dar preferência à contratação das empresas de seus próprios estados. Esse foi um dos motivos pelos quais algumas empreiteiras mineiras e paulistas despontaram como algumas das maiores empreiteiras nacionais (ALMEIDA, 1980; CAMPOS, 2014).

Um momento decisivo da trajetória nacional do setor de infra-estrutura e construção civil foi durante a gestão federal de Juscelino Kubitschek (1956-1961). Ao longo de seu governo, as atividades do setor chegaram a um nível até então inédito, a partir dos empreendimentos previstos pelo Plano de Metas, sobretudo com a construção de Brasília e os seus projetos rodoviários. Foi a partir de então que as maiores empreiteiras passaram a desenvolver atividades de forma mais intensa. Até então, as construtoras eram dominantemente locais e regionais. A partir daquele período, algumas delas principalmente as maiores paulistas, mineiras e cariocas - passaram a desenvolver atividades distribuídas de maneira razoável pelo território brasileiro. Não à toa, a partir daquele momento, elas passaram a se organizar em nível nacional e elaborar projetos e objetivos mais amplos e ousados (BENEVIDES, 1976; CAMPOS, 2014).

Outro momento fundamental da trajetória dessas empresas se deu ao longo da ditadura civil-militar (1964-1988). Nesse período, essas empresas encontraram o momento de maior atividade da história do setor. Com a ampliação dos investimentos em obras públicas e com as inversões do BNH, o volume de projetos tocados chegou a um nível inédito e as maiores empreiteiras brasileiras não só passaram a atuar em diversas regiões do território e com empreendimentos de grande monta, como também passaram a desempenhar ações em outros países. Assim, desde o final da década de 1960, algumas empreiteiras brasileiras começam a exercer atividades internacionais e algumas tornaram-se, já a partir dos anos 1970, verdadeiras multinacionais, chegando a possuir receita fora do Brasil superior à auferida no mercado doméstico (FONTES, 1986; CAMPOS, 2014).

O período da década de 1980 e 1990 é de decadência contínua e ações declinantes nas atividades da construção civil no país. A extinção do BNH e a falta de uma política habitacional clara, em paralelo ao desmonte das estatais e as privatizações fizeram reduzir de maneira contínua os investimentos públicos. As empreiteiras brasileiras passaram então a diversificar suas atividades, adquirindo concessões públicas e ampliando suas atividades no exterior, no caso das maiores empresas. No entanto, o contexto era de crise, escassez e decadência para a construção civil brasileira (BIONDI, 1999; CAMPOS, 2014).

15 No início do século XXI, o setor chegou a presenciar uma certa retomada das atividades da construção civil, com a volta dos investimentos públicos, de grandes projetos de energia e transporte, mais investimentos da Petrobrás com a política de conteúdo nacional e a nova 
edição de um programa habitacional com o Minha Casa Minha Vida, bem como as inversões relacionadas aos grandes eventos da Copa do Mundo Fifa 2014 e as Olimpíadas do Rio de 2016. Essas iniciativas fizeram reaquecer o setor, que logo entrou em crise novamente em meio à depressão econômica do período 2014-2017 e com os efeitos danosos da "Operação Lava-jato", que gerou quebradeira de empresas, desemprego e desnacionalização (CAMPOS, 2018).

Em linhas gerais, essa foi a trajetória do setor da indústria de construção no Brasil no século XX. Vejamos agora de forma breve e resumida como se deu esse processo no Rio de Janeiro, que abriga certas peculiaridades não verificadas em outros estados e na dinâmica nacional.

\section{O setor de construção civil no Rio de Janeiro no século XX}

A construção civil constituiu um dos principais ramos industriais da economia carioca ao longo do século XX. Tendo um processo histórico muito emblemático de urbanização (SINGER, 1969), a cidade contou historicamente com muitas empresas do setor organizadas no Clube de Engenharia e atuando junto ao poder municipal. A cidade do Rio de Janeiro tradicionalmente constituiu o principal ou um dos mais relevantes polos do mercado imobiliário brasileiro, concentrando algumas das maiores empresas e sediando a principal entidade patronal do setor, a Câmara Brasileira da Indústria da Construção (Cbic), desde a sua fundação, no ano de 1957, até a sua transferência para Brasília, nos anos 1990.

18 Já na construção pesada, as seguidas profundas intervenções urbanas sentidas na cidade do Rio de Janeiro e expressas principalmente durante as administrações dos prefeitos Pereira Passos (1902-1906), Carlos Sampaio (1920-1922), Henrique Dodsworth (1937-1945), Francisco Negrão de Lima (1956-1958 e 1965-197 enquanto governador do estado da Guanabara), Carlos Lacerda (governador da Guanabara entre 1960 e 1965) e, já no século XXI, Eduardo Paes (2009-2016) proporcionaram um dinâmico mercado para as atividades das empreiteiras de obras públicas. Não à toa, várias das maiores empresas brasileiras do setor possuem a sua sede nacional na cidade do Rio e também a principal organização empresarial do setor, o Sindicato Nacional da Construção Pesada (Sinicon), mantém a sua sede na cidade desde que ele foi fundado, em 1959. A cidade sofreu grandes intervenções ao longo de sua história, algumas emblemáticas como a remodelação do porto, a construção das avenidas Central e Beira-Mar, o desmonte de alguns morros como o do Castelo, a construção das avenidas Brasil e Presidente Vargas, a adutora Guandu-Leblon, a construção dos túneis Rebouças e Santa Bárbara, as obras da ponte Rio-Niterói, o metrô e as recentes intervenções preparatórias para o recebimento dos grandes eventos: Jogos Pan Americanos de 2007, além das já citadas Copa e Olimpíadas. Apesar da historicidade distinta de cada um desses empreendimentos, com seus contextos e características específicas, prevalece uma tendência de concentração dos serviços e melhoramentos urbanos no núcleo urbano, constituído pela zona Sul, região central da cidade, grande Tijuca e Barra, além do movimento de expulsão das populações subalternas para as periferias e franjas da cidade, como a zona Oeste e a Baixada Fluminense (ABREU, 1988; TRINDADE, 2006). 
19 É preciso destacar que até 1975 a cidade e o estado do Rio de Janeiro correspondiam a unidades administrativas independentes entre si. $\mathrm{O}$ atual município do Rio de Janeiro compunha até 1960 o Distrito Federal e estado da Guanabara dessa data até 1975.0 estado do Rio de Janeiro era até o terceiro quartel do século XX independente da cidade e tinha capital em Niterói. As principais empreiteiras que analisaremos são cariocas e não fluminenses, até porque as empresas do antigo estado do Rio não gozavam de grande expressão no mercado nacional de infra-estrutura. É importante frisar que, apesar das repetidas e contínuas intervenções urbanas na cidade do Rio de Janeiro, que geraram demanda de serviços de obras de infra-estrutura para as empreiteiras cariocas, o estado do Rio de Janeiro não possui um mercado tão ativo nesse tipo de atividade e, além disso, não dispôs de um programa de infra-estrutura como os verificados em São Paulo ou Minas Gerais, sendo o seu Departamento de Estradas de Rodagem (DER-RJ) e empresa de eletricidade (Cerj - Companhia de Eletricidade do Rio de Janeiro) pouco relevantes quando comparados aos dos estados mais dinâmicos.

As empreiteiras cariocas não possuem uma trajetória similar às maiores companhias originadas de São Paulo, Minas Gerais e do Nordeste ao longo do século XX. Ao contrário das maiores paulistas, mineiras e nordestinas, as empreiteiras fluminenses encontraram dificuldades nos anos 1960, 1970 e 1980, no compasso da própria decadência e crise da economia do estado do Rio de Janeiro nesse período, quando a federação dispôs de taxas de expansão inferior à nacional e dos outros estados, perdendo tamanho e importância na produção nacional da riqueza. Como tentaremos comprovar ao longo desse artigo, essa decadência das construtoras do estado do Rio de Janeiro se deveu mais a conflitos políticos do que apenas a debilidades técnicas, econômicas e de gestão dessas companhias.

\section{"O empreiteiro fluminense é antes de tudo um pária"1 - a trajetória das empresas de engenharia do estado do Rio de Janeiro}

O Rio de Janeiro foi o berço das mais antigas empreiteiras brasileiras. A proximidade com a sede do poder nacional, o fato de ser o centro irradiador do primeiro sistema rodoviário nacional (com Rio-São Paulo, Rio-Bahia e Rio-Juiz de Fora) e o capitalizado mercado de obras públicas do antigo Distrito Federal fizeram com que as primeiras empresas relevantes de construção pesada do país fossem cariocas. Inicialmente muito atreladas ao Clube de Engenharia e, depois, a outros sindicatos e associações de classe, as firmas cariocas tiveram historicamente atuação forte no âmbito da sociedade civil e junto ao aparelho de Estado. No entanto, apesar dessa forte atuação política - e muitas vezes em função justamente delas -, as construtoras locais experimentaram trajetória de decadência nos anos 1960 e na ditadura, dando lugar a paulistas, mineiras e nordestinas na liderança do mercado de obras públicas. A cidade continuou sendo centro importante no xadrez da indústria de construção pesada brasileira, mesmo esvaziada da atuação de construtoras locais, sendo indicativo disso a transferência de sede de empresas nordestinas para o Rio, como a Norberto Odebrecht, a Queiroz Galvão e a Delta, além da mineira Andrade Gutierrez. ${ }^{2}$ Essas empresas escolheram a cidade para a sua sede nacional, dada a importância que a antiga capital federal tem no mercado nacional do setor. 
Quadro - Listagem de algumas das principais empreiteiras cariocas no século XX:

\begin{tabular}{|l|l|}
\hline Empresa: & Controladores principais: \\
\hline Affonseca & Fernado Moreira D'Affonseca e família D'Affonseca \\
\hline Carioca & João Carlos Backheuser e família \\
\hline Cavalcanti Junqueira & Colonna Cavalcanti, Haroldo Junqueira e famílias \\
\hline CAVO & José Colagrossi Filho / Camargo Corrêa \\
\hline Civilhidro & Luiz Garcia de Souza \\
\hline Cobrasil & Romeu Sá Freire \\
\hline Concórdia & João Lagoeiro Barbará \\
\hline Contek (origem em ES) & Chafir Elias Saade e família Saad \\
\hline Ecisa & Júlio de B. Barreto / Donald Stewart Jr. \\
\hline Esusa & Hermano Cezar Jordão Freire \\
\hline Ferraz Cavalcanti & Luiz C. B. Cavalcanti; Luiz Ferraz \\
\hline Genésio Gouvêia & Jorge Luiz de la Rocque \\
\hline Geomecânica & Francis Bogossian \\
\hline Koteca & Manoel Vivaqua Vieira / José de Almeida Vieira \\
\hline Metropolitana (CMC) & Sobrinho \\
\hline Metropolitana (CMSA) & Haroldo Cecil Poland / Maurício Alencar e irmãos \\
\hline Portuária (PECP) & Francisco Dias Sant'Anna e família \\
\hline Presidente & Wilson Saad Frahia e família (Carlos e outros) \\
\hline Quattroni & Luigi Quattroni \\
\hline Rodoférrea & Jacyntho Sá Lessa \\
\hline SBU & Paulo de Frontin / Antonio Manuel Siqueira de \\
\hline Sisal & Cavalcanti \\
\hline Sermarso/Sobrenco & Jadir Gomes de Souza \\
\hline Sotege & Sérgio Valle Marques Souza \\
\hline & João Alfredo Castilho \\
\hline
\end{tabular}

Fonte: CAMPOS, 2014

No quadro acima é possível verificar a listagem de algumas das principais empreiteiras fundadas no Rio ao longo do século XX. Vejamos inicialmente algumas das principais peculiaridades que marcaram o perfil e a trajetória das empreiteiras fluminenses. Em primeiro lugar, é intensa a presença dessas firmas no mercado imobiliário, ao contrário de algumas mineiras e paulistas, que se especializaram basicamente em obras públicas. A importância do setor de imóveis do Rio, bem como as viradas e incertezas políticas dos anos 1960 e 1970 na região, podem ser fatores explicativos dessa tendência.

Além disso, as cariocas e fluminenses foram tardias na criação de um sindicato regional. Enquanto em São Paulo havia uma associação de empreiteiros desde fins da década de 1940 - a Associação Paulista dos Empreiteiros de Obras Públicas (Apeop), fundada na capital paulista em 1947 - e, em Minas, um sindicato do setor em fins da década de 1960 Sindicato da Construção Pesada de Minas Gerais (Sicepot-MG), formado em 1968 -, o Rio só viu o advento de organização similar em 1975, quando, junto com a fusão do estado do Rio e da Guanabara, foi fundada a Associação dos Empreiteiros do Estado do Rio de Janeiro (AEERJ), que tinha dentre seus objetivos a adoção de políticas protecionistas para as empreiteiras locais, o que era prática deliberada em Minas, São Paulo e Paraná. Um dos motivos que explica o caráter tardio desse aparelho da sociedade civil é o fato de a cidade ser sede de organizações nacionais do setor, como o Sinicon, que contava com uma maioria de filiados e direção dominada por empreiteiras cariocas nos anos 1960 e 1970, além de outras associações que continham empreiteiros, como o Clube de Engenharia e o Sinduscon-Rio (Sindicato da Indústria da Construção Civil do Rio de Janeiro, ex-AICC Associação da Indústria da Construção Civil). 
24 Há de assinalar, por fim, uma última característica específica das empreiteiras cariocas, que diz respeito à sua proximidade e intensa atuação junto a agências contratantes federais. $O$ fato de a cidade do Rio de Janeiro constituir a capital do país até 1960 e de dispor da sede de várias autarquias e empresas estatais nacionais demandantes de obras públicas fez com que muitas empreiteiras fluminenses possuíssem uma estreita presença nesses organismos. Assim, várias empresas de construção da cidade e do estado assumiram historicamente contratos para construção, melhoramento, reforma e pavimentação de rodovias junto ao Departamento Nacional de Estradas de Rodagem (DNER). Dessa forma, a especialidade principal das empreiteiras brasileiras, a construção rodoviária, é verificada especialmente nas construtoras fluminenses, responsáveis por várias estradas federais do país. Da mesma forma, o fato de na cidade estar a sede da Petrobrás, Eletrobrás e Banco Nacional de Habitação (BNH) fez com que muitas empreiteiras fluminenses tivessem uma inserção particular nessas agências estatais, muito relevantes para a dinâmica do mercado de obras públicas do país.

Os efeitos de uma guinada política podem ser percebidos na trajetória de duas empresas. A Sociedade Brasileira de Urbanismo (SBU) foi fundada no início da década de 1930 por integrantes do Clube de Engenharia, sendo uma empresa com forte ligação com o grupo político de Vargas, do interventor Henrique Dodsworth e, depois, do PSD carioca. Essas ligações foram importantes para a empresa ter obras e desenvolver uma liderança no setor, sendo esta a empresa que conduziu o processo de formação da Associação Brasileira dos Empreiteiros de Obras Públicas (Abeop), criada no Rio em 1953 e que acabou não vingando. No entanto, a empresa encontrou dificuldades ao longo de sua trajetória, conforme relato de empreiteiro anônimo entrevistado por Galeno Tinoco Ferraz Filho:

Como nosso cliente é o governo, os aspectos políticos influem de maneira decisiva..,. Existia aqui (Rio de Janeiro) uma empresa - quando ainda não se falava muito de construção rodoviária - muito importante. Chamava SBU (Sociedade Brasileira de Urbanismo). Essa empresa foi fundada em 1932 pelo Paulo de Frontin e era a mais importante aqui do antigo estado da Guanabara, antigo Distrito Federal. A SBU cresceu brutalmente. Fez de tudo aqui: Cristo Redentor, estrada da Tijuca, viaduto das Canoas, forte de Copacabana, toda a pavimentação de concreto dessas estradinhas, canal que liga a Lagoa ao mar, etc... Era uma empresa muito grande para a época. Para você ter uma idéia de como esse negócio de política influi, a SBU era preliminarmente, ligada ao Getúlio e, em consequência, àquele grupo PSD que governou por longo tempo o Distrito Federal. Quando Lacerda foi eleito governador na Guanabara a SBU tinha com o governo do Estado, 28 contratos de obras. Seis meses depois tinha um. Fechou, é claro. São questões absolutamente políticas (FERRAZ, 19814, p. 96-97).

26 A companhia tentou continuar funcionando, pré-qualificou-se para o metrô do Rio em 1969 (O EMPREITEIRO, 1969A), mas não levou a obra e logo deixou de existir.

27 A empresa de Luigi Quattroni, um dos fundadores do Sinicon em 1959, teve trajetória semelhante. Responsável por obras de estradas de rodagem e pelo túnel Rebouças, o empresário tinha ligações políticas semelhantes à SBU. Também foi à bancarrota com o governo Lacerda, conforme relato do mesmo empreiteiro entrevistado por Ferraz Filho:

Você quer um outro dado, de um outro empreiteiro, nas mesmas condições? Foi um grande empreiteiro aqui na Guanabara, que eu conheço, porque inclusive trabalhou comigo em estradas de rodagem - o Quatroni. Pois o Quatroni tinha uma senhora empresa. Foi ele quem fez o túnel Rebouças. Quando o Lacerda assumiu o Governo do Estado estava contratando com ele. E não deu outra. Tiraram-lhe o Túnel Rebouças e ele faliu (FERRAZ, 1981, p. 97). 
28

A gestão Lacerda, com o aparente fito de enfraquecer o grupo empresarial ligado ao getulismo na antiga capital, inaugurou prática que virou costumeira no Rio, a de abrir o mercado de obras local para empresas de outros estados, dando-lhes inclusive preferência. Algumas construtoras cariocas entraram em decadência após a implementação dessa orientação política. Emblemático disso foi a dificuldade que tivemos para estabelecer a data da fundação de algumas construtoras do estado. Algumas empresas locais, no entanto, parecem ter sido beneficiadas na gestão lacerdista, como a Brascan-Light, que fez no período a adutora Guandu-Leblon, e a Carvalho Hosken, ligada à secretária Sandra Cavalcanti e que ficou com contratos de urbanização em áreas de favelas removidas da zona Sul (O EMPREITEIRO, 1972).

Outras empresas do Rio importantes antes dos anos 1960 eram a Sotege, a Rodoférrea, a Companhia Auxiliar de Viação e Obras (CAVO), a Cavalcanti Junqueira, a Ferraz Cavalcanti e a Genésio Gouveia. Todas elas pertencem ao grupo das firmas que fundaram o Sinicon em 1959 (SINICON, 1959) e tinham então obras no Rio e fora da capital. Apesar de decadente ao longo do regime civil-militar, a Genésio Gouveia obteve lote para pavimentação e melhoramento da Belém-Brasília em 1972 e participava do seleto grupo das empresas que atuavam em hidrelétricas, tendo feito as obras da UHE de Curuá-Uma (40 MW), no Pará (O EMPREITEIRO, 1972; 1973). Outra carioca decadente na ditadura e que também construía barragens era a Cavalcanti Junqueira, que participou das obras das usinas de Estreito, no rio Grande, e Porto Colômbia, em Goiás, associada a outras empresas (O EMPREITEIRO, 1969B; 1969C; 1972B). A CAVO era a firma de José Colagrossi Filho, diretor do Sinicon, que foi comprada pela Camargo Corrêa em 1956, na estratégia da empreiteira paulista de estabelecer um braço na então capital federal (QUINTELLA, 2008). A Serviços de Engenharia Rodoférrea S.A. pertencia a Jacyntho Sá Lessa e participou das obras de Brasília e da Ferrovia do Aço (O EMPREITEIRO, 1976). A Sociedade de Terraplanagem e Grandes Estruturas, a Sotege (ex-Castilho), era controlada pelo engenheiro João Alfredo Castilho, fundador, primeiro presidente e proprietário do escritório-sede do Sinicon até os dias atuais (SINICON, 1959). Castilho era ligado a Kubitschek e, após construir a ponte da Amizade entre o Brasil e o Paraguai durante o governo JK, sua empresa ergueu e deu ao presidente uma casa no país vizinho com o formato das iniciais de seu nome, em um terreno doado pelo ditador Alfredo Strossner (PRADO, 1997), o que gerou acusações contra a empreiteira. A Portuária (PECP) era uma tradicional construtora carioca de Galba de Boscoli, contribuinte do Instituto de Pesquisas e Estudos Sociais (Ipes), que atuou no golpe de 1964, e que foi comprada pela baiana Concic em 1973 (DREIFUSS, 1981, p. 641).

Outro empresário tradicional do ramo no Rio era o engenheiro mineiro Sérgio Valle Marques Souza, criador e dono da Sermarso (Sérgio Marques Souza S.A.), fundada no Rio em 1953, e da Sobrenco (Sociedade Brasileira de Engenharia e Comércio S.A.), de 1957. As duas empresas foram fundidas em 1969, mantendo o nome da segunda. A Sobrenco era especializada nas chamadas obras de arte especiais, ou melhor, pontes e viadutos, sendo responsável, com outras, pela ponte Rio-Niterói e, sozinha, pela ponte do Paranoá (projetada por Niemeyer e então com a maior viga de concreto do mundo), trecho da Brasília-Acre e pelo viaduto Paulo de Frontin, no Rio Comprido, que teve a queda de um de seus módulos durante a obra, em 1971. Na ocasião do acidente, o Clube de Engenharia, no qual Souza exercia forte atuação, saiu em defesa da empresa, argumentando erro de projeto, mas a companhia e o presidente acabaram maculados desde então. A empresa 
decaiu, saiu do consórcio construtor da ponte Rio-Niterói, então em obras, e depois foi à falência (O EMPREITEIRO, 1968; 1969A; 1969C; 1971; 1972A; LEAL, 1985, p. 62).

31 Apesar dos fracassos empresariais por conflitos políticos, havia os empresários próximos dos militares e dos novos governantes pós-1964. Jadir Gomes de Souza era um dos controladores da empreiteira Sisal, de construção de edifícios urbanos, como o prédio do Rio Othon Palace Hotel, em Copacabana. Souza era amigo pessoal e jogava cartas periodicamente com o ditador Arthur da Costa e Silva, além de ter financiado o Ipes antes do golpe. A empresa cresceu na ditadura, mas era mais voltada para a construção imobiliária, tendo participado da ampliação e recuperação de oito hotéis em Angola no início dos anos 1980 (O EMPREITEIRO, 1974; 1982; 1983; GASPARI, 2002; DREIFUSS, 1981).

Mais que a empresa de Jadir Gomes de Souza, a construtora carioca com relações mais profundas com os militares e grupos multinacionais que participaram do golpe e do regime foi a Companhia Metropolitana de Construções (CMC). Propriedade nos anos 1970 dos irmãos Mário, Maurício e Marcelo Nunes Alencar e de Frederico Gomes da Silva ${ }^{3}$, a empreiteira era dirigida no início dos anos por 60 Haroldo Cecil Poland, que presidiu o Sinicon de 1960 a 1962 e colaborou ativamente com o Ipes, além de ser próximo do coronel Golbery do Couto e Silva e de Carlos Lacerda. Ele foi um personagem central no golpe de 1964, sendo um articulador do empresariado com a cúpula militar responsável pela derrubada da democracia e do governo João Goulart. A empresa foi fundada em 1933 e fora responsável por trechos da estrada presidente Dutra, da São Paulo-Curitiba, da RioBahia, da rodovia dos Imigrantes, do aeroporto de Curitiba, barragens, oleodutos, as obras de Brasília, dentre outros projetos que a enquadravam como uma das maiores do país na primeira metade dos anos 1970, quando sua posição na lista das maiores empreiteiras do país oscilava de $6^{\circ}$ ao $9^{\circ}$ lugar, de acordo com a revista O Empreiteiro (CAMPOS, 2014). Em colaboração ao projeto político do coronel Mário Andreazza de se postular como candidato a presidente da República, os donos da Metropolitana arrendaram os jornais Correio da Manhã e Última Hora, respectivamente em 1969 e 1972 (WAINER, 1988). O objetivo era reorientar a linha editorial de impressos diários de grande circulação que possuíam um viés mais independente e crítico em relação à ditadura, medida de interesse do regime e que, por outro lado, tinha a intenção de formar um mecanismo de projeção dos interesses, dos projetos e do poder dos empreiteiros de obras públicas junto à população de uma forma mais ampla. Apesar do porte econômico e prestígio político, a empresa foi à falência no final de 1974, com atrasos nos pagamentos a receber, endividamento e recusa de bancos de rolagem de suas dívidas. A revista O Empreiteiro indicou má administração como a causa da quebra da empresa, mas as circunstâncias parecem indicar um rompimento político, dada a ligação da empresa ao grupo de Andreazza, parcialmente marginalizado na transição entre os governos Médici e Geisel. Um dos donos da empresa, Marcelo Alencar, foi suplente de senador pelo MDB, cassado com o AI-5 e depois ingressou no PDT de Leonel Brizola, tornando-se prefeito e governador do Rio após a democratização (O EMPREITEIRO, 1975).

Se a Metropolitana teve seu brilho interrompido em meados da ditadura, as cariocas que tiveram mais vigor ao longo do regime foram a Ecisa e a Esusa. A Engenharia, Comércio e Indústria S. A. (Ecisa) foi fundada em 1949 no Rio por Julio de B. Barreto. Seis meses depois, o filho de canadenses e estudante da Escola Nacional de Engenharia, Donald Stewart Junior, ingressou na empresa e ascendeu em seu interior até se tornar presidente com a morte de Barreto. A firma foi responsável por obras como trecho da estrada RioBahia, estação de tratamento do Guandu, obras de Brasília, o paulista hospital das 
Clínicas, edifício-sede do Banco do Brasil em Brasília, trecho da ferrovia do Aço, além de uma rodovia na Tanzânia. Suas especialidades eram as obras portuárias e metroviárias, tendo a Ecisa feito terminais para a Petrobrás, porto de Maceió, obras em estaleiros, terminal de contêineres em São Paulo, ampliação de porto no Paraguai, além de trechos dos metrôs do Rio e de São Paulo. Apesar da atuação no setor de obras públicas, outro ponto forte da companhia eram as edificações comerciais urbanas e sua exploração, como o shopping center Conjunto Nacional de Brasília e supermercados no Rio. Segundo a revista O Empreiteiro, a empresa foi ascendente na década de 1970, chegando a ser sexta maior do país em 1978, enquanto a revista Exame a apontava como quarta construtora nacional naquele ano (CAMPOS, 2014). Com o desempenho, Donald Stewart foi homenageado como homem de construção do ano de 1977 pela revista O Empreiteiro, com a seguinte justificativa:

[...] é fato notório que o sucesso das maiores construtoras brasileiras se deve em boa parte às relações políticas de que gozam seus diretores proprietários. A Ecisa constitui-se uma rara exceção. Sediada no Rio de Janeiro - um mercado francamente aberto a todos - e sem um 'apadrinhamento transcendente', como afirma Donald Stewart Jr., presidente da empresa, a Ecisa esbarrou em toda sorte de obstáculos ao tentar ingressar nos mercados de outros estados. A maior dificuldade era justamente o protecionismo às construtoras locais, praticado sob várias formas veladas e sutis. Mas uma agressiva política de diversificação permitiu consolidar uma posição em diversas frentes - que vão hoje de hospitais e metrôs até portos e centros comerciais, os quais são inclusive explorados comercialmente através de uma subsidiária - possibilitando um ritmo relativamente firme de expansão e, principalmente, conseguir atravessar as sucessivas crises do mercado de construção sem grandes arranhões. (O EMPREITEIRO, 1977, p. 3)

Donald Stewart agradeceu a escolha da revista e "estendeu a homenagem a toda equipe da empresa" (O EMPREITEIRO, 1977). Em 1983, a revista Exame escolheu a empresa como empreiteira do ano pelo seu desempenho frente à crise (SINICON, 1984).

A empresa tinha extensa ramificação para agropecuária, centros comerciais, mineração, além de ter adquirido a empreiteira Coenge em 1977. No entanto, a construtora foi à concordata em 1978, após um atraso nos pagamentos da Companhia do Metropolitano do Rio de Janeiro. A Ecisa tinha então $50 \%$ de seu faturamento proveniente das obras do metrô carioca e, segundo Stewart, o encaminhamento do caso se deveu à contratante, que "por uma certa intenção que por declarações à imprensa [sic] altamente desabonadoras à Ecisa e completamente desnecessárias, levaram que a rede bancária se fechasse completamente, não renovando mais a nossa dívida". Apesar do golpe na empresa, seu presidente afirmou: "ressalto porém que não vejo nenhuma conotação política nesse caso" (O EMPREITEIRO, 1980). Com o pedido de concordata, a Ecisa perdeu o contrato e sofreu um processo de decadência, levando Stewart a ser um crítico do setor bancário, dos atrasos nos pagamentos do governo e das associações do setor, tidas por ele como pouco ativas. Chegou a processar a Cia. do Metrô do Rio e, depois, a Açominas, em atitude pouco comum entre os empreiteiros, que em geral alegavam temer as retaliações que poderiam ser tomadas por medidas judiciais contra órgãos contratantes. Stewart foi aplaudido no setor por essas decisões e esboçou projeto de se tornar uma liderança empresarial, participando das atividades do Instituto Liberal no início dos anos 1980. A empresa tentou uma reação em 1983, mas novamente sofreu com atrasos e poucos contratos até ir a falência logo em seguida (DREIFUSS, 1989; CAMPOS, 2014).

A curva ascendente e decadente da trajetória da Ecisa durante a ditadura tem certo paralelo com o percurso da Esusa (Empresa de Serviços Urbanos S. A.). Presidida por 
Hermano Cezar Jordão Freire, a empresa teve várias obras importantes no Rio em seu porta-fólio, como trecho da linha do metrô, o Riocentro, a estrada Teresópolis-Nova Friburgo, a urbanização da Lagoa Rodrigo de Freitas e da orla de Copacabana, o viaduto da Mangueira, prospecção de petróleo e a linha Lilás, com os viadutos 31 de Março e do Santo Cristo ligando o túnel Santa Bárbara à zona portuária. A empresa também atuou no exterior, com a realização de dois hotéis no Iraque, tendo uma sede no Paraguai, para sondar obras na América do Sul, e era atuante no setor imobiliário, com empreendimentos financiados pelo BNH. Com as obras acumuladas, a Esusa saiu da $44^{\mathrm{a}}$

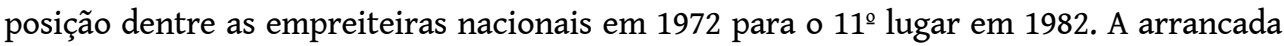
fez com que Freire fosse escolhido o homem de construção do ano pela revista 0 Empreiteiro em 1979. A estratégia da empresa incluía nunca fazer com que um contrato equivalesse a mais do que 20 ou $30 \%$ do seu faturamento total, de modo a evitar o problema que ocorreu com a Ecisa. Esse modus operandi não evitou sua falência em dezembro de 1983, momento em que o mesmo ocorria com outras empreiteiras do país (O EMPREITEIRO, 1978; 1979; 1983; CAMPOS, 2014).

Por fim, a empresa que teve ascensão no fim da ditadura e que virou a principal empreiteira do Rio no pós-regime é a Carioca Engenharia. Foi fundada em 1947 por João Carlos Backheuser, descendente de Everardo Backheuser, espécie de intelectual orgânico do setor construtor na Primeira República, quando reclamava casas populares para as classes de baixa renda (MATTOS, 2008) ${ }^{4}$. A construtora iniciou sua trajetória com obras no subúrbio do Rio, constando como construtora de pequeno ou médio porte durante a ditadura, sempre abaixo da $30^{\mathrm{a}}$ posição nacional no setor nesse período. Com foco regional e local, a empresa teve seu salto nos governos Brizola, quando foi responsável por parte das obras do sambódromo e por um total de 140 dos 506 Centros Integrados de Educação Pública (Ciep's) construídos, o que a gabaritou a fazer os CEU's (Centro Educacional Unificado) paulistas posteriormente. Em 1988, adquiriu a Christiani-Nielsen, tradicional empreiteira dinamarquesa estabelecida no Brasil e com sede no Rio desde 1922, especializada em obras portuárias e responsável por projetos emblemáticos como o Maracanã, o Jockey Clube, o elevador Lacerda em Salvador, o píer Mauá, o Terminal Marítimo da Baía de Ilha Grande (Tebig), o porto de Tubarão, o porto de Rio Grande, dentre outros. Com isso, foi formada em 1992 a Carioca Christiani-Nielsen Engenharia (CCNE), que, na última década do século $\mathrm{XX}$, foi alçada à posição de uma das maiores empreiteiras do país. Participou das privatizações, sendo uma das controladoras do suprimento de água e esgoto para Niterói e de rodovias com pedágios no estado do Rio (O EMPREITEIRO, 1984; 1985; CAMPOS, 2014).

\section{Conclusões:}

38 As empreiteiras cariocas lideraram, ao lado de mineiras e paulistas, a construção de Brasília e as grandes obras nacionais do período Kubitschek, tomando a iniciativa de fundar o Sinicon em 1959 e dominando o órgão em seus primeiros anos. De 1960 a 1980, no entanto, dadas as injunções econômicas e políticas no estado da Guanabara e no país, perderam espaço para empresas de São Paulo, de Minas e do Nordeste. O protagonismo inicial deu lugar a uma relativa decadência e perda da centralidade, visível de maneira mais ampla em diversos segmentos da economia fluminense após a transferência da capital para Brasília. 
39 A atual crise econômica e fiscal do Rio de Janeiro tem sido abordada por certas perspectivas críticas a partir dos equívocos adotados na condução política do estado na última década. Sem negar a validade dessa explicação, entendemos que é necessário agregar à mesma fatores históricos menos recentes e aspectos mais estruturais para a compreensão da questão. 0 esvaziamento da economia fluminense constitui um processo que já remonta a um período superior a 50 anos. 0 que se verificou no caso da trajetória das empreiteiras fluminenses foi sentido em vários outros ramos econômicos no estado do Rio, que entraram em decadência após a transferência da capital para Brasília e que sentiram especialmente os efeitos da crise dos anos 1980. Longe de constituir um processo advindo exclusivamente das forças do mercado ou derivado de uma dinâmica estritamente econômica, entendemos que essa crise prolongada do Rio resulta em boa medida da posição periférica assumida pelo estado na correlação de forças entre os diferentes grupos empresariais-políticos que dominam a cena nacional desde o período da ditadura e também é fruto do conflito distributivo da arrecadação tributária estabelecido entre as unidades da federação desde os anos 1980, em caráter desvantajoso para o erário fluminense. Dessa forma, a crise da economia fluminense desde a transferência da capital para Brasília e a submersão das empresas de construção pesada do estado parecem se encontrar em suas causas profundas, que podem ser encontradas em conflitos políticos estabelecidos entre grupos empresariais em torno da liderança sobre o Estado capitalista brasileiro.

\section{BIBLIOGRAFIA}

ABREU, Maurício de Almeida. Evolução Urbana do Rio de Janeiro. $2^{\underline{a}}$ ed. Rio de Janeiro: IpanRio / Zahar, 1988 [1987].

AEERJ. AEERJ 30 Anos: 30 anos de obras públicas no Rio de Janeiro (1975-2005). Rio de Janeiro: AEERJ, 2005.

ALMEIDA, Júlio Sérgio Gomes de; DAIN, Sulamis; ZONINSEIN, Jonas. Indústria de Construção e Política Econômica Brasileira do Pós-Guerra: relatório de pesquisa. Rio de Janeiro: IEI/UFRJ, 1982

ALMEIDA, Márcio. Estado e Energia Elétrica em São Paulo: CESP, um estudo de caso. Dissertação de mestrado. Campinas: Unicamp, 1980.

BENEVIDES, Maria Victoria. O Governo Juscelino Kubitschek: desenvolvimento econômico e estabilidade política, 1956-61. Rio de Janeiro: Paz e Terra, 1976.

BIONDI, Aloysio. O Brasil Privatizado: um balanço do desmonte do Estado. São Paulo: Perseu Abramo, 1999.

CAMPOS, Pedro Henrique Pedreira. Estranhas Catedrais: as empreiteiras brasileiras e a ditadura civil-militar. Niterói: Eduff, 2014.

CAMPOS, Pedro Henrique Pedreira. "Capital estrangeiro no setor brasileiro de infraestrutura: história e situação atual". In: Jornal dos Economistas. Edição de fevereiro de 2018. Rio de Janeiro: Corecon-RJ, 2018. 
CARVALHO, Luiz Maklouf. Cobras Criadas: David Nasser e O Cruzeiro. $2^{a}$ ed. São Paulo: EdSENACSP, 2001.

CASTRO, Ana Célia. As Empresas Estrangeiras no Brasil. Rio de Janeiro: Zahar, 1979.

CHAVES, Marilena. A Indústria de Construção no Brasil: desenvolvimento, estrutura e dinâmica. Dissertação de mestrado em Economia Industrial. Rio de Janeiro: UFRJ, 1985

DRAIBE, Sônia. Rumos e Metamorfoses: Estado e industrialização no Brasil, 1930-1960. Rio de Janeiro: Paz e Terra, 1985.

DREIFUSS, René Armand. 1964: a conquista do Estado. Petrópolis: Vozes, 1981.

DREIFUSS, René Armand. O Jogo da Direita na Nova República. $2^{\mathrm{a}}$ ed. Petrópolis: Vozes, 1989 [1989].

GASPARI, Elio. A Ditadura Envergonhada. São Paulo: Companhia das Letras, 2002.

HOBSBAWM, Eric J. Era dos Extremos: o breve século XX, 1914-1991. $2^{\mathrm{a}}$ ed. São Paulo: Companhia das Letras, 1998 [1994].

LEAL, Paulo Nunes. O Outro Braço da Cruz. Rio de Janeiro: Editora do autor, 1985.

O EMPREITEIRO. Edição de setembro de $1968, \mathrm{n}^{\circ} 8$.

O EMPREITEIRO. Edição de agosto de 1969, nº 19 (1969A).

O EMPREITEIRO. Edição de novembro de 1969, nº 22 (1969B).

O EMPREITEIRO. Edição de dezembro de 1969, nº 23 (1969C).

O EMPREITEIRO. Edição de abril de 1971, nº 39.

O EMPREITEIRO. Edição de abril de 1972, nº 51 (1972A).

O EMPREITEIRO. Edição de outubro de 1972, nº 57 (1972B).

O EMPREITEIRO. Edição de julho de 1973, nº 66.

O EMPREITEIRO. Edição de julho de 1974, nº $^{\circ} 8$.

O EMPREITEIRO. Edição de janeiro de 1975, nº 80

O EMPREITEIRO. Edição de outubro de 1976, nº 105.

O EMPREITEIRO. Edição de dezembro de 1977, nº 119.

O EMPREITEIRO. Edição de maio de 1978, nº 124.

O EMPREITEIRO. Edição de julho de 1979, nº 138.

O EMPREITEIRO. Edição de janeiro de 1980, nº 144.

O EMPREITEIRO. Edição de dezembro de 1982, nº 181.

O EMPREITEIRO. Edição de dezembro de 1983, nº 193.

O EMPREITEIRO. Edição de julho de 1984, nº 200.

O EMPREITEIRO. Edição de julho de 1985, nº 212.

FERRAZ Filho, Galeno Tinoco. A Transnacionalização da Grande Engenharia Brasileira. Dissertação de mestrado em Economia. Campinas: Unicamp, 1981.

FONTES, Virgínia. Rupturas e Continuidades na Política Habitacional Brasileira, 1920-79. Dissertação de mestrado em História. Niterói: UFF, 1986. 
FURTADO, Celso. Formação Econômica do Brasil. 27ํㅗ ed. São Paulo: Companhia Editora Nacional / Publifolha, 2000 [1959].

O GLOBO. Edição de 11 de fevereiro de 2011.

MARX, Karl. "Introdução à Contribuição para a Crítica da Economia Política" [1857]. In: Marx: Manuscritos econômico-filosóficos e outros textos escolhidos. Coleção Os Pensadores. São Paulo: Abril Cultural, p. 109-131, 1974.

MATTOS, Romulo Costa. Pelos Pobres! As campanhas pela construção de habitações populares e o discurso dobre as favelas na Primeira República. Tese de doutoramento em História. Niterói: UFF, 2008.

MENDONÇA, Sonia Regina de. O Patronato Rural no Brasil Recente (1964-1993). Rio de Janeiro: EdUFRJ, 2010.

PRADO, Lafayette Salviano. Transportes e Corrupção: um desafio à cidadania. Rio de Janeiro: Topbooks, 1997.

QUINTELLA, Wilson. Memórias do Brasil Grande: a história das maiores obras do país dos homens que as fizeram. São Paulo: Saraiva / Vigília, 2008,

SAES, Flávio Azevedo Marques de. A Grande Empresa de Serviços Públicos na Economia Cafeeira. São Paulo: Hucitec, 1986.

SINGER, Paul. Desenvolvimento Econômico e Evolução Urbana. São Paulo: Companhia Editora Nacional, 1969.

SINICON. Ata da reunião de fundação do Sinicon. 10 de março de 1959.

SINICON. Informe Sinicon. Edição de 23 de julho de 1984, Ano I, nº 22.

TAVARES, Maria da Conceição. Da Substituição de Importações ao Capital Financeiro. $7^{\mathrm{a}}$ ed. Campinas: EdUNICAMP, 1978 [1972].

TRINDADE, Claudia Peçanha da. Entre a Favela e o Conjunto Habitacional: programa de remoção e habitação provisória (1960-1970). Dissertação de mestrado em História. Niterói: UFF, 2006.

VILAR, Pierre. "História marxista, história em construção". In: LE GOFF, Jacques; NORA, Pierre (org.). História: novos problemas. Rio de Janeiro: Francisco Alves, p. 146-178, 1976.

WAINER, Samuel. Minha Razão de Viver. Rio de Janeiro: Record, 1988 [1987].

\section{NOTAS}

1. Frase enunciada por Haroldo Guanabara, diretor do Sinicon e da AEERJ, na Revista Construir no 4, de maio de 1989 apud AEERJ, 2005. p. 131.

2. A empresa possuía escritório no Rio, cidade onde mora a família Andrade, e, em 2011, anunciou a transferência da sede de operações de engenharia de São Paulo para o Rio, focando projetos relacionados às Olimpíadas e à Copa do Mundo. O GLOBO, 2011, p. 16.

3. Frederico Gomes da Silva era um advogado ligado ao jornalista David Nasser e prestava consultorias para outras construtoras. Ver CARVALHO, 2001, p. 383-454.

4. Backheuser também era atuante na Sociedade Nacional de Agricultura, conforme indicou MENDONÇA, 2010, p. 264-98. 


\section{RESUMOS}

O presente artigo pretende analisar a história da indústria da construção pesada do Rio de Janeiro ao longo do século XX. Problematizando as formas de intervenção do Estado na economia e as peculiaridades da indústria carioca, a análise se detém na trajetória das empresas nascidas no estado, verificando os diferentes papeis assumidos pelas mesmas durate o século XX no mercado nacional de infra-estrutura. Apesar de sediar uma quantidade bastante expressiva de agências estatais contratadoras de serviços de engenharia - como a Petrobrás, o DNER e o BNH, durante a ditadura - a cidade do Rio nem sempre dispôs das empreiteiras mais poderosas do país, tendo em vista os audaciosos projetos alternativos realizados em São Paulo e Minas Gerais, além de uma série de disputas políticas locais e nacionais que levaram à decadência de algumas construtoras cariocas.

This article intends to analyze the history of the heavy construction industry of Rio de Janeiro throughout the 20th century. By problematysing the state's intervention in the economy and the peculiarities of the industry of Rio de Janeiro, the analysis stops in the trajectory of the companies born in the state, verifying the different roles assumed by them during the period in the national infrastructure market. In spite of hosting a very significant amount of state agencies hiring engineering services - such as Petrobrás, DNER and the BNH, during the dictatorship - the city of Rio not always had the most powerful contractors in the country, due to the bold alternative projects carried out in São Paulo and Minas Gerais, as well as a series of local and national political disputes that led to the decline of some construction companies in Rio.

El presente artículo pretende analizar la historia de la industria de la construcción pesada de Río de Janeiro a lo largo del siglo XX. Problematizando las formas de intervención del Estado en la economía y las peculiaridades de la industria carioca, el análisis se detiene en la trayectoria de las empresas nacidas en el estado, verificando los diferentes papeles asumidos por las mismas durante el período en el mercado nacional de infraestructura. A pesar de ser sede de una cantidad bastante expresiva de agencias estatales contratadoras de servicios de ingeniería - como Petrobrás, el DNER y el BNH, durante la dictadura - la ciudad de Río no siempre dispuso de las contratistas más poderosas del país, teniendo en vista los audaces proyectos alternativos realizados en São Paulo y Minas Gerais, además de una serie de disputas políticas locales y nacionales que llevaron a la decadencia de algunas constructoras cariocas.

Le présent article vise à analyser l'histoire de l'industrie de la construction lourde de Rio de Janeiro tout au long du 20ème siècle. Em discutant des formes d'intervention de l'État dans l'économie et les particularités de l'industrie de Rio, l'analyse se tient dans la trajectoire des entreprises nées dans l'état, la vérification des différents rôles assumés par elles pendant le XXe siècle dans le marché national $d$ 'infrastructure. Bien que siège d'un nombre très important d'agences gouvernementales qui utilisent des services d'ingénierie - comme la Petrobras, le DNER et le BNH pendant la dictature - la ville de Rio n'a pas toujours disposé des entreprises de construction les plus puissantes dans le pays, compte tenu des projets alternatifs audacieux réalisés à São Paulo et Minas Gerais, ainsi qu'une série de conflits politiques locaux et nationaux qui ont conduit à la décadence de certains constructeurs de Rio. 
ÍNDICE

Mots-clés: Industrie de construction lourde; entrepreneurs; Rio de Janeiro; industrialisation

Keywords: Heavy construction industry; contractors; Rio de Janeiro: industrialization

Palabras claves: Industria de construcción pesada; contratistas; Rio de Janeiro; industrialización

Palavras-chave: Indústria da construção pesada; empreiteiras; Rio de Janeiro; industrialização

\section{AUTOR}

\section{PEDRO HENRIQUE PEDREIRA CAMPOS}

Doutor em História pela UFF, professor da UFRRJ. Correio eletrônico: phpcampos@yahoo.com.br. A pesquisa que deu origem a este artigo contou com o apoio da Faperj e do CNPq. 